\title{
Evaluating Access to Riyadh's Planned Public Transport System Using Geospatial Analysis
}

Alma Al Hussaini, Nourah Al Hosain 


\section{About KAPSARC}

The King Abdullah Petroleum Studies and Research Center (KAPSARC) is a non-profit global institution dedicated to independent research into energy economics, policy, technology and the environment across all types of energy. KAPSARC's mandate is to advance the understanding of energy challenges and opportunities facing the world today and tomorrow, through unbiased, independent, and high-caliber research for the benefit of society. KAPSARC is located in Riyadh, Saudi Arabia.

This publication is also available in Arabic.

\section{Legal Notice}

(C) Copyright 2021 King Abdullah Petroleum Studies and Research Center ("KAPSARC"). This Document (and any information, data or materials contained therein) (the "Document") shall not be used without the proper attribution to KAPSARC. The Document shall not be reproduced, in whole or in part, without the written permission of KAPSARC. KAPSARC makes no warranty, representation or undertaking whether expressed or implied, nor does it assume any legal liability, whether direct or indirect, or responsibility for the accuracy, completeness, or usefulness of any information that is contained in the Document. Nothing in the Document constitutes or shall be implied to constitute advice, recommendation or option. The views and opinions expressed in this publication are those of the authors and do not necessarily reflect the official views or position of KAPSARC. 


\section{Key Points}

The planned public transport project in Riyadh city is one of the city's main approaches to help alleviate road congestion, emissions, and reduce domestic fuel consumption.

This study uses geographic information system analysis to measure the accessibility of public transport stations being developed in Riyadh.

This study evaluated accessibility to the stations by calculating the number of residential buildings covered within five and 10 minutes' walking and driving distance to the stations, based on Riyadh's road network.

Results from the analyses provide insights into where improvements need to be made to improve the accessibility and enhance the usability of public transport in Riyadh. 


\section{Summary}

he King Abdulaziz Project for Public Transport in Riyadh city is one of the world's largest urban transit systems being developed. The project aims to meet the demands of the city's growing urban population while reducing traffic congestion, heavy private car dependence and air pollution. The performance of any public transport system largely depends on its accessibility. Therefore, this study evaluates the population's access to Riyadh's public transport stations using network analysis tools based on geographic information systems. We analyze Riyadh's road network to calculate the areas of accessibility from residential buildings around Riyadh's 85 metro stations and three levels of bus network stations. We consider various modes of travel under different scenarios. The results of the analysis show that:

$34 \%$ and $74 \%$ of Riyadh's population can drive to a metro station within five and 10 minutes, respectively.

$5 \%$ and $14 \%$ of the city's population can walk to a metro station within five and 10 minutes, respectively.

$53 \%$ and $76 \%$ of the population can walk to a bus station within five and 10 minutes, respectively. 


\section{Introduction}

mart cities are crucial for sustainably accommodating urban growth. Individuals in academia and governments define the term 'smart city' differently. However, the core concept relates to connecting a city's different components through advanced technology to continually improve and enhance its services and facilities (Albino, Dangelico, and Berardi 2015). One of the most important services offered in cities with growing populations is public transport.

Public transport systems are necessary for transportation in cities with high population growth rates. They provide proven economic, social and environmental benefits to cities and their citizens. Investments in public transport provide economic benefits by creating jobs in the manufacturing and operation phases. Public transport usage may also reduce vehicle ownership costs for citizens, shifting consumer spending to other sectors of the economy. Such a shift can provide both social and economic benefits (Weisbrod and Reno 2009) and improve local communities' living standards. The latter is a key objective of the Saudi Vision 2030 strategic framework.

Gulf Cooperation Council (GCC) countries are experiencing high population growth and urbanization rates, with its population expected to double by 2050 (AECL 2018). The Kingdom of Saudi Arabia is the largest country in the GCC, and the population of its cities tripled between 1980 and 2018. Presently, nearly $80 \%$ of the Kingdom's total population lives in cities (AECL 2018). These statistics confirm Saudi Arabia's vast urbanization. Moreover, they highlight the need for sustainable and healthy urban development as the Kingdom's population continues to grow.

The regional concentration of its population, particularly in cities, is a major challenge that Saudi Arabia's government is trying to address with its development plans (UN-Habitat 2019). Specifically, the Kingdom has developed the National Transformation Program, whose strategic objectives align with those of the Vision 2030 framework. Objectives 2.3.1 and 2.3.2 of this program aim to enhance the quality of services in cities and the urban landscape to accommodate the growing population (Vision 2030 2018).

Figure 1 shows the percentage of the total population in Saudi Arabia's main regions from 1992 to 2017. Riyadh is the only region where the number of people as a percentage of the total population continually increased. Riyadh, Saudi Arabia's capital and largest city, was home to $25.12 \%$ of the total Saudi population in 2017, up from $22.63 \%$ in 1992. The city's population is expected to increase further owing to population growth and the internal migration of residents from other areas, mainly for work opportunities (RUO 2016). 
Figure 1. Percentage of the total population in Saudi Arabia's main regions over time.

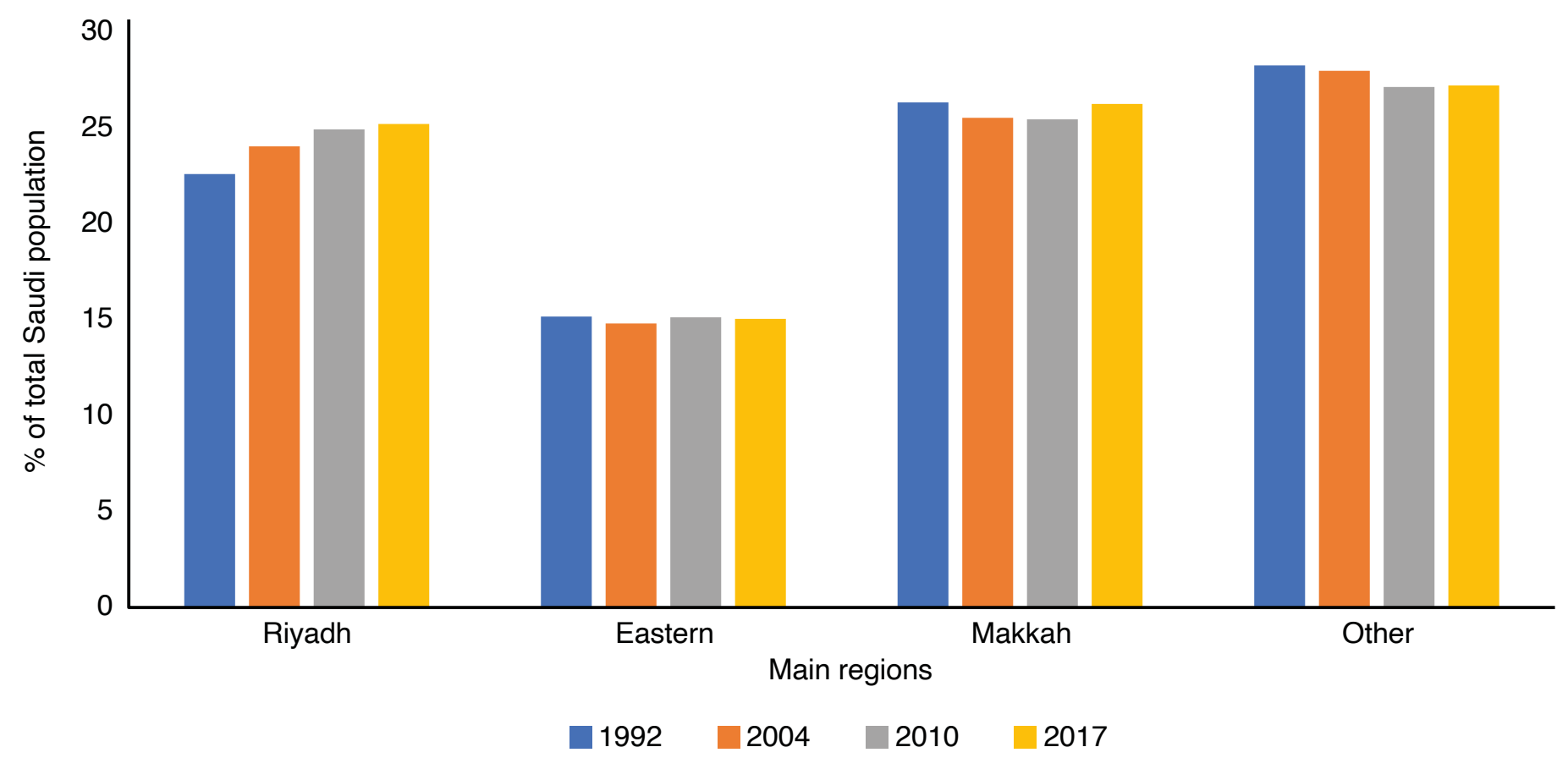

Source: GASTAT.

In Riyadh, $77 \%$ of people use cars as their main mode of transportation, mainly owing to the lack of efficient public transportation and pedestrian roads (RCRC 2016). In 2017, the number of cars per 1,000 people reached 310 , an increase from 274 cars per 1,000 people in 2013 (RUO 2017). This heavy car dependence has generated high levels of car ownership, congested roads and pollution. The growing domestic demand for fuel resulting from car ownership may also reduce Saudi Arabia's oil export potential.

To address these issues, the Royal Commission for Riyadh City (RCRC) developed the Riyadh Public Transportation Plan, which was approved in December 2011 (RCRC 2012). This plan was created to minimize the economic and environmental damage from current transport behavior and accommodate Riyadh's population growth. The project aims to fulfil the growing population's demand for transportation, reduce traffic congestion and limit private car usage.

Riyadh's public transport project will develop one of the world's largest urban transit systems. The system will include 176 kilometers $(\mathrm{km})$ of metro lines and 85 stations covering Riyadh's most populated areas. The plan also includes a parallel bus network, with stations connecting all districts. The bus network consists of three levels: bus rapid transit (BRT), community buses and feeder buses. BRT will use a dedicated lane that ensures a traffic-free journey. Community and feeder buses will operate across and within neighborhoods, respectively, with no dedicated lanes (Riyadh Metro 2020a). According to Alwalid Alekrish, the RCRC's deputy Chief Executive Officer for Programs and Projects, the first three metro lines are expected 
to serve around 1.2 million passengers per day. However, the ridership will grow to 3.6 million in the longer term (Briginshaw 2019). In general, the initial projections of metro and bus ridership are low to account for social distancing, which is currently necessary to contain the spread of COVID-19.

This study presents a methodology for assessing access to Riyadh's public transport system in terms of people's ability to reach stations. Accessibility is important for the system to achieve its expected ridership goals. We conduct an analysis based on geographic information systems (GIS) to estimate the percentage of the city's population with access to public transport stations under different accessibility modes and scenarios.

Measuring accessibility is vital for evaluating the success of the planned public transport project. It is also helpful in providing recommendations regarding transit-oriented development (TOD) projects around metro stations. However, it is important to acknowledge that accessibility is not a standalone measure of success. Instead, consumer preferences, policies (e.g., congestion charges) and other factors can also contribute to the project's success. These topics are not covered in this analysis. 
he transportation planning literature has long discussed the concept of accessibility. Its importance as a key indicator of urban form and policy is underscored by the increasing interest in sustainable development (Benenson et al. 2011). Hansen (1959) proposed the first definition of accessibility in the planning field, describing it as "the potential of opportunities for interaction." Since then, the concept has been refined and enriched by subsequent research (Cascetta, Cartenì, and Montanino 2016; Curtis and Scheurer 2010; El-Geneidy and Levinson 2002; Levinson 2014).

Studies have proposed various measures to assess and improve the level of accessibility provided to a city's population by its transport system (Curl, Nelson, and Anable 2015). Baradaran and Ramjerdi (2001) identify five approaches for measuring accessibility: travel cost, gravity or opportunity, constraint-based, utility-based surplus and composite measures. Geurs and Van Wee (2004) propose classifying these measures into infrastructure-, location-, person- or utility-based. According to Curl, Nelson, and Anable (2011), studies use location-based accessibility measures most frequently. More recently, Mavoa et al. (2012) use three categories to assess transit accessibility measures. These categories are access to transit stops, duration of the public transit journey and access to destinations via public transit.

According to Mavoa et al. (2012), most studies of public transit accessibility consider physical access, that is, proximity to a transit stop (Currie 2010; Lovett et al. 2002). A specific location's accessibility is typically determined by calculating that location's service areas. The two methods for performing such calculations that are commonly used in the literature are Euclidean buffers and network buffers. The latter takes the road infrastructure into account and therefore produces more realistic results because it considers potential barriers (Zhao et al. 2003). The network buffer method mitigates errors that may arise with the Euclidean buffer method (Kraft 2016).

The Euclidean and network buffer methods can be performed in ArcGIS using the Buffer command and the Generate Service Areas tool, respectively. ArcGIS is a GIS application, and its tools have been used extensively in the literature to perform network analyses (Ford et al. 2015; O'Sullivan, Morrison, and Shearer 2000). Various GIS methods are used to measure access to public transport stations, including creating isochrone maps, generating buffers and creating service areas (Kraft 2016). Our analysis also uses the Build Network Dataset tool. This tool allows users to build a local version of the street network in the analysis area and define and regularly update the network's properties. ArcGIS can also be used to calculate the costs of alternative modes of transportation to different destinations (Ford et al. 2015). Thus, GIS enables users to evaluate the components of a planned public transport system and provide recommendations for further enhancement.

The distance or time required for a person to travel to a transit stop is a fundamental element of access to that stop. In this analysis, we define time constraints based on previous literature and the walking and driving conditions in the Kingdom. A study published by the Directorate-General for Regional and Urban Policy in Europe considers the accessibility of transit stations in large European cities. They define a bus station as accessible if it can be reached in no more than a five-minute walk. A metro station is accessible if it can be reached within a 10-minute walk. They use population distribution and street network data to show that $75 \%$ to $95 \%$ of the population in 14 large European cities have access to transit (Poelman and Dijkstra 2015). We consider similar definitions of accessibility 
in our study because the method used in their analysis is similar to ours.

This analysis, to our knowledge, is one of the first studies to measure access to the planned metro and bus stations in Riyadh. Our methodology, however, is not unique; it has been used to measure access to public transport stations worldwide. 


\section{Input Data and Methodology}

\section{Input Data}

We collected the necessary data to analyze the accessibility of Riyadh's public transport stations from different sources and validated the data (Table 1). The road network layer extracted from Open Street Map (OSM) includes the names, classes, speed limits and lengths of roads. It also includes some other factors. We manually checked the names and classes of roads and matched them with the OSM base map on ArcGIS Pro and Riyadh GeoPortal. The speed limits of many streets were missing in the source layer. To avoid inconsistencies, we used the average recorded speed limit per class category from the 2019 road design guide report by the Ministry of Municipal and Rural Affairs (MoMRA) (Table 2). For pedestrian roads, we used an average walking speed of 5 kilometers per hour (km/h) (Kasehyani et al. 2019). Street lengths were validated using the Calculate Geometry function in ArcGIS.

The Riyadh land use layer for 2016 classifies the city's buildings into different categories. For this analysis, we only consider buildings in the residential category. This category includes 17 sub-categories. We retained 12 in our data and removed the other five categories that do not reflect residential buildings. ${ }^{1}$

Table 1. Input data and sources used for the accessibility analysis.

\begin{tabular}{l|l} 
Input Data & Source \\
\hline Riyadh Road Network & OSM \\
\hline Riyadh Land Use Layer & RCRC \\
\hline Public Transport Stations Layer & $\begin{array}{l}\text { RCRC, cross-referenced with Riyadh GeoPortal and the Riyadh } \\
\text { Metro website }\end{array}$
\end{tabular}

Source: MoMRA (2019).

Table 2. Average speed limit per road category.

\begin{tabular}{l|l|l} 
MoMRA Class & OSM class & Average speed $(\mathbf{k m} / \mathbf{h})$ \\
\hline Expressway & Motorway, Motorway-link, Trunk, Trunk-link & 90 \\
\hline Arterial & Primary, Primary-link & 65 \\
\hline Collector & Secondary, Secondary-link & 55 \\
\hline Local & $\begin{array}{l}\text { Residential, Tertiary, Living street, Service, } \\
\text { Tertiary-link, Unclassified, Unknown }\end{array}$ & 40
\end{tabular}

Source: MoMRA (2019)

\footnotetext{
${ }^{1}$ The excluded sub-categories of the residential category are commercial center, manufacturing plant, mixed use building that is not an apartment building, office building and warehouse.
} 


\section{Methodology}

his study uses GIS network analysis tools to determine the proportion of Riyadh's population with access to public transport stations under different scenarios. We define a bus or metro station as accessible if it can be reached within a specific time frame by a specific travel mode. To access Riyadh's public transport network, a passenger can walk directly to a metro station if it is within an accessible range. Alternatively, a passenger may walk to a nearby bus station and connect to the metro via the bus.
Passengers may also choose to drive to the metro owing to the current lack of pedestrian road infrastructure in Riyadh and the harsh summer weather. According to Riyadh Metro (2020b), 25 of Riyadh's 85 metro stations have park and ride spaces. These spaces allow passengers to park their cars and use metro services (Figure 2). Although only some stations offer the park and ride facility, we consider all stations in our analysis of driving access to the metro. Free street parking is abundant in Riyadh, and a passenger can be dropped off at a station by a private vehicle or taxi.

Figure 2. Riyadh Metro stations.

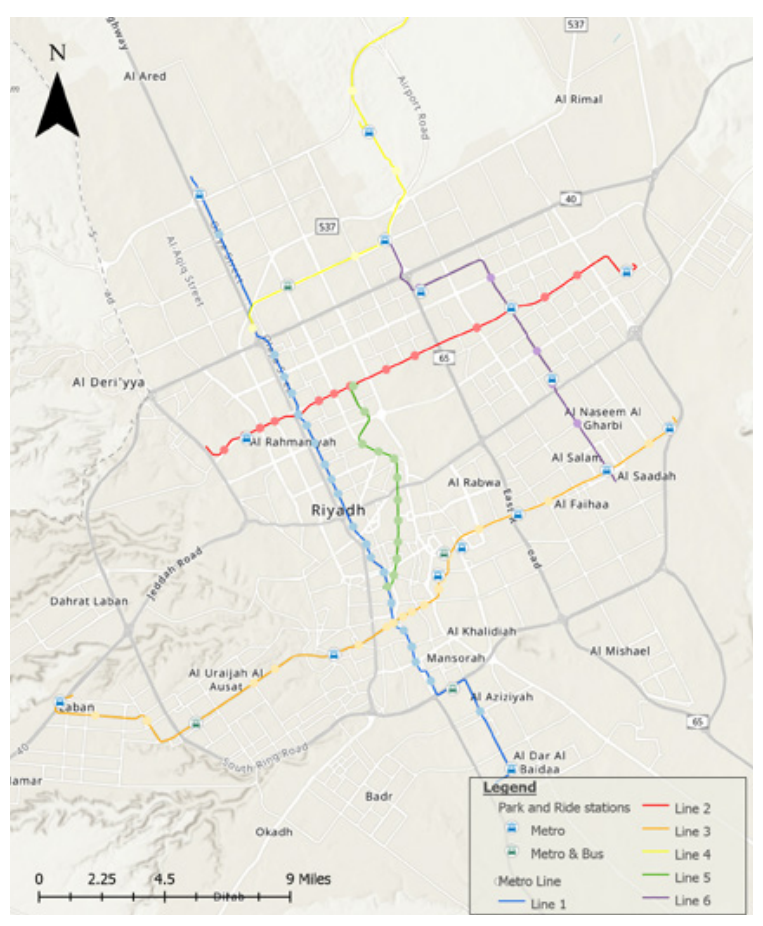

Source: KAPSARC analysis.

Transit station service areas are the regions around each station that can be reached within a specified time interval. They are calculated using network-based spatial analysis tools provided by Esri (Figure 4). As described earlier, Riyadh's actual road network is used to create the network dataset. This dataset includes a set of edges that represent links or roads and a set of junctions that connect edges. It also contains a set of turns that can be combined to define the permissible movements between two or more edges. Our analysis uses time as the impedance in the following scenarios. 
Figure 3. Riyadh bus network.

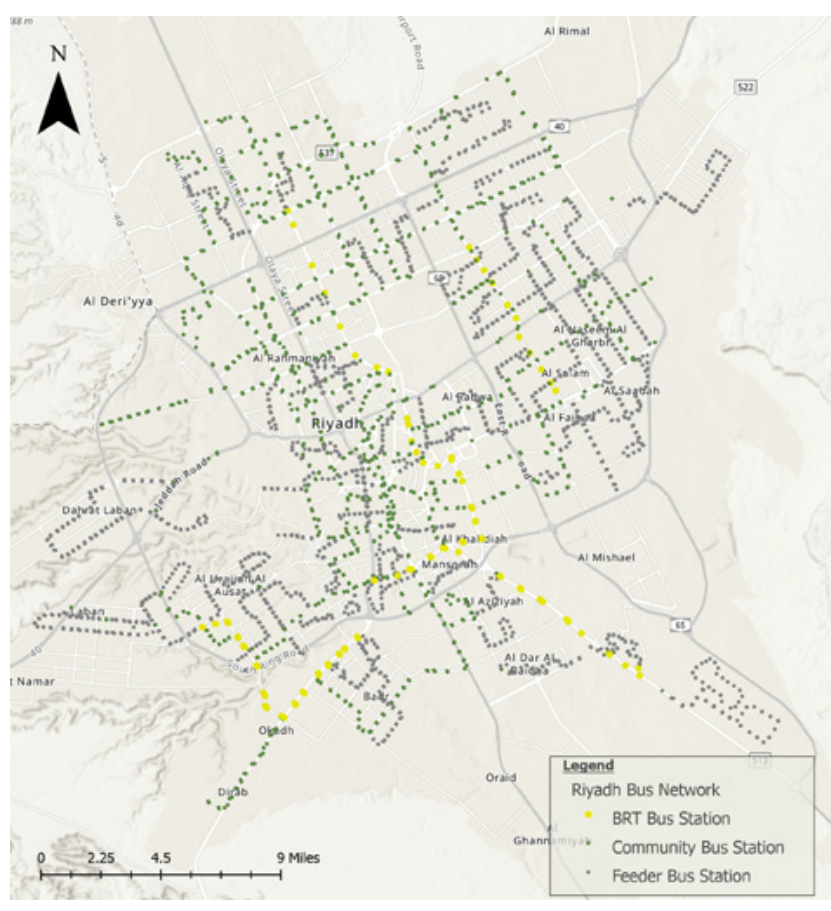

Source: KAPSARC analysis.

\section{- Driving}

We consider two scenarios for this travel mode: driving times of five and 10 minutes to reach a station during peak traffic conditions. The network analysis tool provides an option to consider live traffic conditions when calculating service areas in the driving scenario. However, given the COVID-19 pandemic and Riyadh's 24-hour curfew at the time of the analysis, live traffic data did not reflect normal conditions. Thus, we consider Riyadh's average traffic during the peak travel hours of 7 a.m. and 5 p.m. in 2019. The TomTom Traffic Index (2020) estimates this traffic to be around $40 \%$. Using this value, we accordingly adjust the maximum driving times of five and 10 minutes to 3.5 and seven minutes, respectively, around each station. In other words, we expect a car to cover the same distance within 3.5 minutes under free-flow traffic conditions as it can cover within five minutes during peak hours.
Travel time is calculated for each edge by dividing its length in kilometers by its speed in $\mathrm{km} / \mathrm{h}$. The result is multiplied by 60 to convert it to minutes.

Edges classified by the OSM as path, pedestrian, steps or footway are prohibited in this mode, and each edge has a specified direction of flow.

- Walking

We analyze two scenarios for this travel mode: walking times of five and 10 minutes to reach a station.

Travel time is calculated for each edge by dividing its length in kilometers by the average walking speed of $5 \mathrm{~km} / \mathrm{h}$. The result is multiplied by 60 to convert it to minutes. 
Edges classified by OSM as trunk, trunk-link, motorway or motorway-link are prohibited in walking mode, as they are neither safe nor designated for walking.

After calculating the service areas, we overlay Riyadh's land use layer to calculate the number of residential dwellings covered by these areas in each scenario. These calculations account for Riyadh's residential vacancy rate, which was $8 \%$ in 2016 (RUO2017). The resulting number of occupied households is then multiplied by 5.7, which was the average household size in Riyadh in 2016 (RUO 2017). The result is the percentage of the population with access to a public transport station in each scenario.

Figure 4. Example service area around a station.

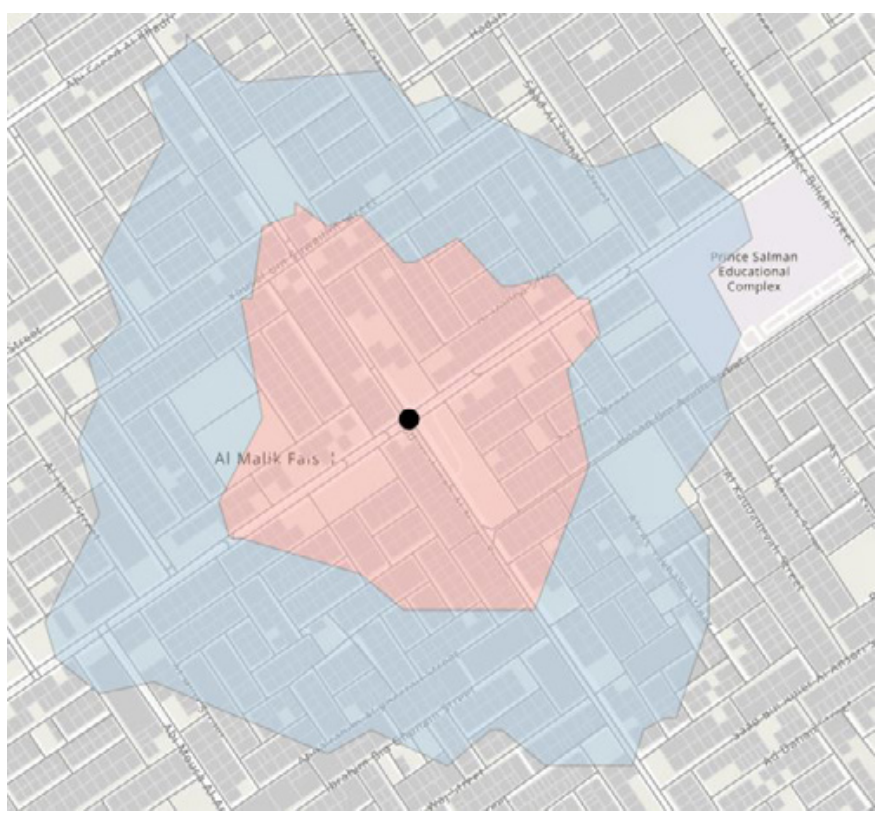

Legend

Bus stop

Road network

Residential building

Service area within a five-minute walk

Service area within a 10-minute walk

Source: KAPSARC analysis. 


\section{Results and Discussion}

his study evaluates accessibility by calculating travel times. We consider the time it takes to reach accessible stations from the nearest points to residential buildings on Riyadh's road network. Figures 5-10 show the generated service areas for the scenarios considered in this analysis.

Figure 5 shows the accessible areas around Riyadh's 85 metro stations within 10-minute and five-minute drives. Based on 2016 population data, around $74.3 \%$ of Riyadh's citizens can drive from their residence to a metro station within 10 minutes. The percentage of the population that can access a metro station within a five-minute drive is around
$34.4 \%$. Notably, the time required to find a parking space, the time taken to travel from a point of origin to a vehicle and from a vehicle to a destination are not incorporated into this analysis. Thus, the total travel time including parking may be greater than the times specified in this analysis.

Four of the 85 metro stations (Qasr Al Hokm Station, King Abdullah Financial District Station, Western Station and Olaya Station) are iconic stations that are located in highly populated areas. These stations aim to cover and serve a high percentage of the population. Our analysis shows that these four stations are accessible for around $25 \%$ of the residential population within a 10-minute drive.

Figure 5. Service areas around metro stations within five- and 10-minute drives.

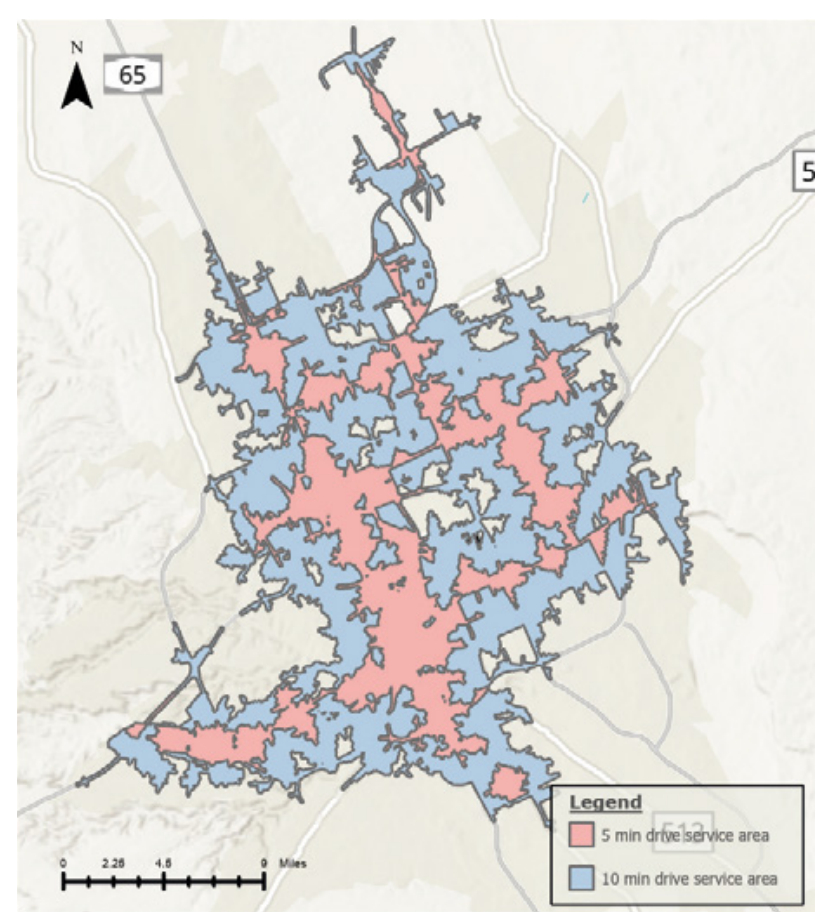

Source: KAPSARC analysis. 
Figure 6. Service areas around metro stations within five- and 10-minute walks.

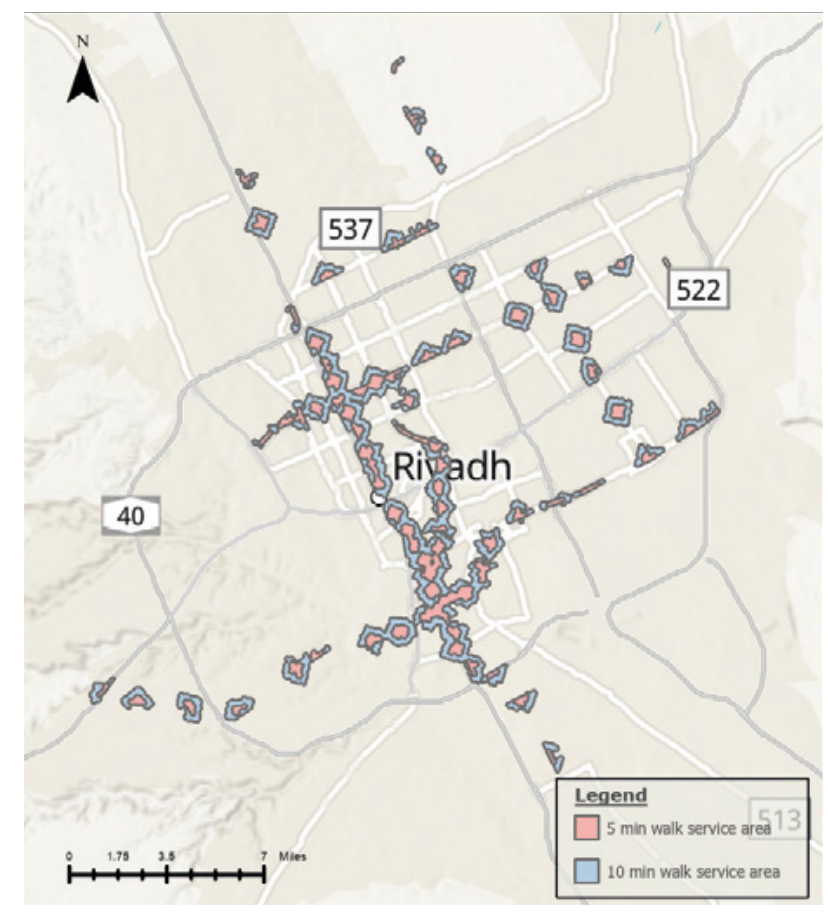

Source: KAPSARC analysis.

We also investigate pedestrian access to metro stations (Figure 6). Around $13.5 \%$ and $4.8 \%$ of the population can walk to a metro station within 10 and five minutes, respectively.

For buses, we consider walking scenarios to evaluate the accessibility for each of the three bus levels separately. Figure 7 shows the areas from which feeder line stations are accessible by walking. Our data show that around $35.8 \%$ and $55.6 \%$ of the population can walk to a feeder station within five and 10 minutes, respectively.

Nineteen community bus lines have been planned to connect residential districts. Figure 8 shows that around $48.2 \%$ of Riyadh's population can reach a community line station on foot within 10 minutes. Around $24.0 \%$ of the population is within a five-minute walk of a station.

Finally, BRT buses have three dedicated lanes to avoid traffic. Figure 9 shows the service areas in which a BRT station can be reached on foot within five and 10 minutes. The analysis shows that around $2.9 \%$ and $8.0 \%$ of the population can walk to a BRT station within five and 10 minutes, respectively. For BRT stations, we consider driving scenarios as well because these lines are mainly located on primary or secondary roads (Figure 10). We find that around $20.3 \%$ of the population can drive to a BRT station within five minutes, and around $55.6 \%$ can do so within 10 minutes. Table 3 summarizes the results for all of the scenarios. 
Figure 7. Service areas around feeder bus stations within a five- or 10-minute walk.

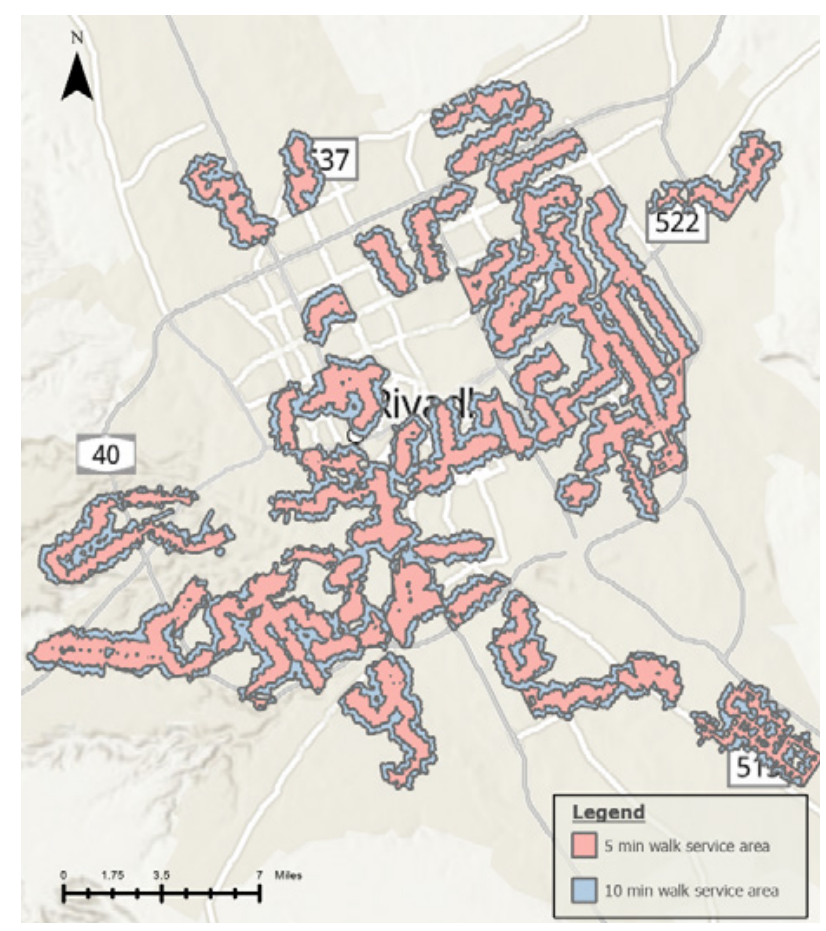

Source: KAPSARC analysis.

Figure 8. Service areas around community bus stations within a five- or 10-minute walk.

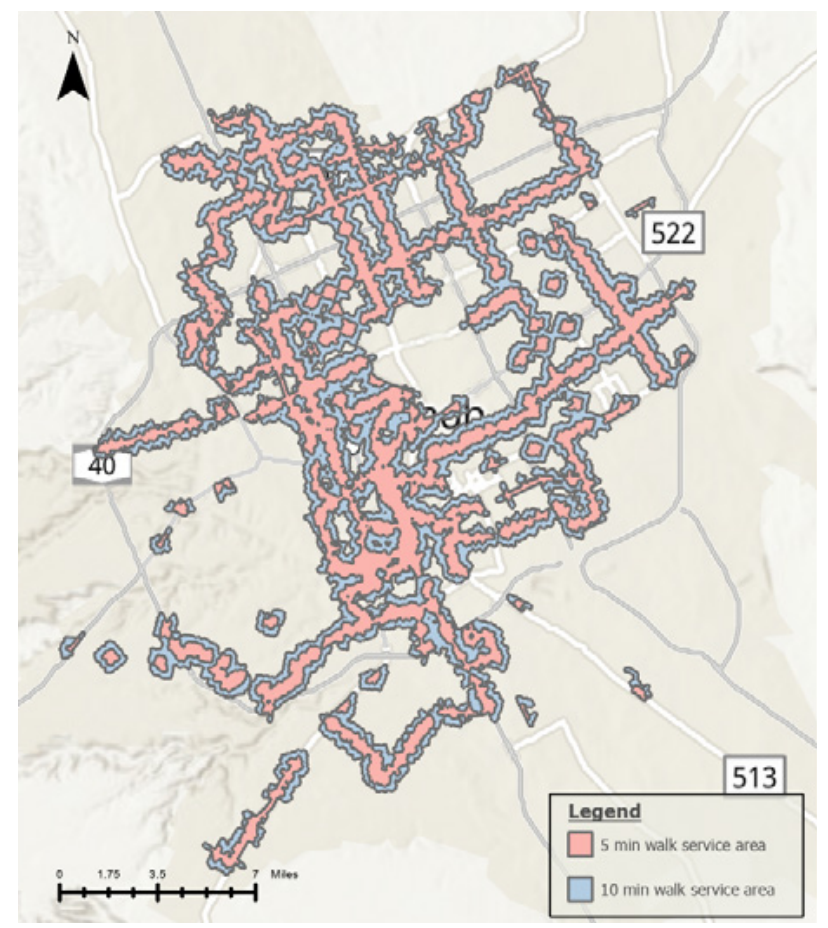

Source: KAPSARC analysis. 
Figure 9. Service areas around BRT bus stations within a five- or 10-minute walk.

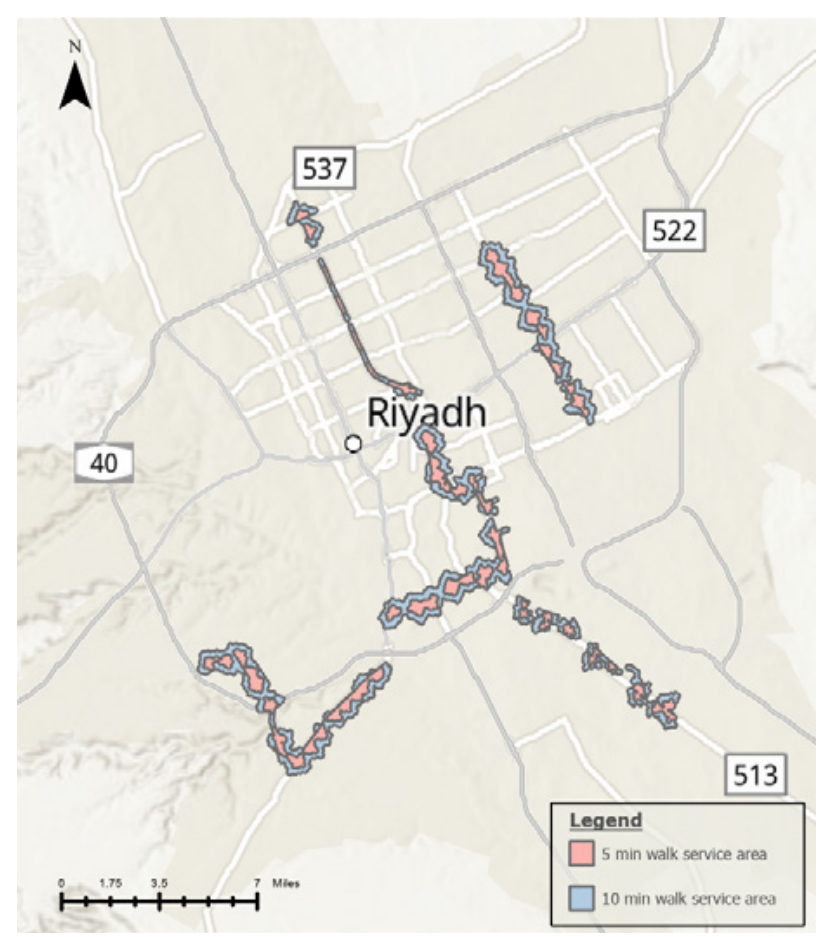

Source: KAPSARC analysis.

Figure 10. Service areas around BRT bus stations within a five- or 10-minute drive.

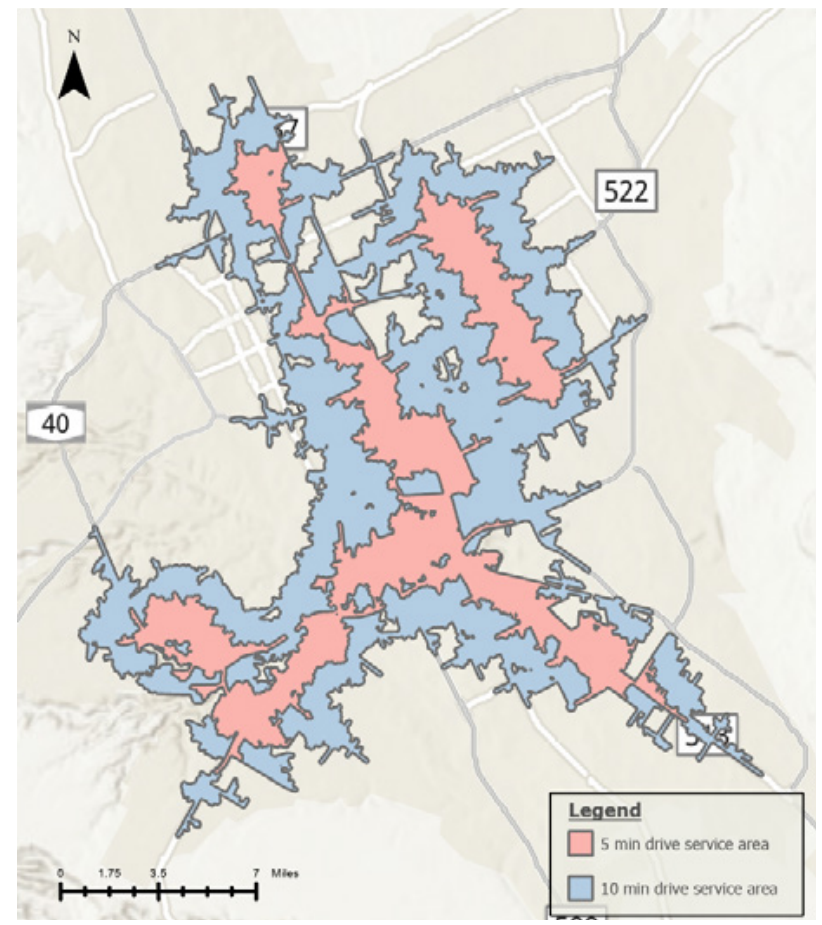

Source: KAPSARC analysis. 
Table 3. Population accessibility analysis results.

\begin{tabular}{l|l|l|l} 
Scenario & $\%$ of population with access & Scenario & $\%$ of population with access \\
\hline Metro - 10-min drive & $74.3 \%$ & BRT - 10-min drive & $55.6 \%$ \\
\hline Metro - 5-min drive & $34.4 \%$ & BRT - 5-min drive & $20.3 \%$ \\
\hline Metro - 10-min walk & $13.5 \%$ & BRT - 10-min walk & $8.0 \%$ \\
\hline Metro - 5-min walk & $4.8 \%$ & BRT - 5-min walk & $2.9 \%$ \\
\hline Feeder - 10-min walk & $55.6 \%$ & Community - 10-min walk & $48.2 \%$ \\
\hline Feeder - 5-min walk & $35.8 \%$ & Community - 5-min walk & $24.0 \%$
\end{tabular}

Source: KAPSARC analysis.

The results show that metro station usage in Riyadh will depend largely on accessibility through driving, as the metro's walking accessibility is clearly very low. To access the metro by walking for 10 minutes or less, most users must walk to the nearest bus station. They can then reach the metro station by bus. The low walking accessibility identified by this analysis is not surprising. Riyadh's vast urbanization has shifted its road infrastructure from a historically pedestrian-friendly layout to a highway-intensive network.

These results can help identify potential improvements to increase access to the stations and estimate possible ridership during the initial launch. If a larger percentage of users are given pedestrian access to metro stations, congestion and emission rates will decrease, as fewer users will drive to these stations. Investments in road infrastructure design, increased pedestrian roads, pedestrian traffic lights and potential financial incentives can help enable this outcome. Additionally, all of the bus levels except for BRT provide more walking accessibility than the metro stations do. Riyadh has more BRT stations than metro stations. However, the BRT stations are distributed in the center of the city, whereas the metro stations cover all sections of Riyadh. 


\section{Conclusion}

his study estimates the potential number of people within the city of Riyadh with access to the public transport system. The methods and travel times used to evaluate accessibility were based on a review of the global public transport accessibility literature. Currently, a large proportion of Riyadh's population can access the metro by driving. Around $74 \%$ of the population is within a 10-minute drive of a metro station, and around 34\% is within a five-minute drive.

Smaller percentages of the population are within an acceptable walking distance to the stations. Specifically, $5 \%$ and $14 \%$ of the population can walk to a metro station within five and 10 minutes, respectively. We find that $53 \%$ and $76 \%$ of the population can walk to a bus stop within five and 10 minutes, respectively. However, these values may change with continued improvements to the city's road structures. These improvements could include installing pedestrian crossings at traffic lights and sidewalks, among others. Combining this analysis with studies on modal shift and consumer choice can provide more useful input for TOD projects around potential metro stations. In the future, analyses of this type may be used when building new metro stations around specific neighborhoods or adding or changing the locations of bus stations.
The method used in this study provides an overall acceptable approximation of public transport stations' accessibility. However, the results can be further improved by updating the road network, the land use layers, and household size and traffic congestion data. The land use layer that was used in this analysis is from 2016. Applying an updated layer can provide a better understanding of population accessibility. For traffic congestion, a general value for the entire city was incorporated into the driving times considered in the analysis. Considering live traffic may alter the results, as congestion is not just time-specific but also road-specific. To further improve the results, household size should be defined differently for Saudi and non-Saudi households. Moreover, different household sizes should be used for different dwelling types.

Overall, developing the public transport system in Riyadh will have major economic, societal and environmental benefits. These benefits include job creation, reduced traffic accidents and emissions reductions, among others. The public transport system in Riyadh is the city's most ambitious effort to control congestion and emissions and improve overall transit. This system will potentially improve transport efficiency, increase density living and provide valuable economic returns to the city. 


\section{References}

Advanced Electronics Company (AECL). 2018. "Smart Cities - The Next Stage Of Urbanization In KSA." Accessed December 15, 2020. https://www. aecl.com/media/2371/urbane.pdf

Albino, Vito, Rosa Maria Dangelico, and Umberto Berardi. 2015. "Smart Cities: Definitions, Dimensions, Performance, and Initiatives." Journal of Urban Technology 22(1):3-21. Accessed December 15, 2020. Smart Cities: Definitions, Dimensions, Performance, and Initiatives (usp.br).

Arriyadh Urban Observatory (RUO). 2016.

"Population Study of Riyadh City (1437H)." Accessed December 15, 2020. https://www.rcrc.gov.sa/en/ research/population-study-of-riyadh-city-1437$\%$ d $9 \% 87 \%$ d9\% $\% 0$

- - . (RUO). 2017. "Riyadh City Urban Indicators - 1438H." Accessed December 15, 2020. https://www.rcrc.gov.sa/en/research/ riyadh-city-urban-indicators-1438h

Baradaran, Siamak, and Farideh Ramjerdi. 2001. "Performance of Accessibility Measures in Europe." Journal of Transportation and Statistics 4(2/3):31-48.

Benenson, Itzhak, Karel Martens, Yodan Rofé, and Ariela Kwartler. 2011. "Public Transport Versus Private Car GIS-based Estimation of Accessibility Applied to the Tel Aviv Metropolitan Area." The Annals of Regional Science 47(3):499-515.

Briginshaw, David. 2019. "Riyadh Metro Closes in on Completion." International Railway Journal, September 27. Accessed December 15, 2020. https://www.railjournal.com/in_depth/ riyadh-metro-completion
Cascetta, Ennio, Armando Cartenì, and Marcello Montanino. 2016. "A Behavioral Model of Accessibility Based on the Number of Available Opportunities." Journal of Transport Geography $51: 45-58$.

Curl, Angela, John D. Nelson, and Jillian Anable. 2011. "Does Accessibility Planning Address What Matters? A Review of Current Practice and Practitioner Perspectives." Research in Transportation Business \& Management 2:3-11.

- - . 2015. "Same Question, Different Answer: A Comparison of GIS-based Journey Time Accessibility with Self-Reported Measures from the National Travel Survey in England." Computers, Environment and Urban Systems 49: 86-97.

Currie, Graham. 2010. "Quantifying Spatial Gaps in Public Transport Supply Based on Social Needs." Journal of Transport Geography 18(1):31-41.

Curtis, Carey, and Jan Scheurer. 2010. "Planning for Sustainable Accessibility: Developing Tools to Aid Discussion and Decision-making." Progress in Planning 74(2):53-106.

El-Geneidy, Ahmed M., and David M. Levinson. 2006. "Access to Destinations: Development of Accessibility Measures." Retrieved from the University of Minnesota Digital Conservancy. https:// hdl.handle.net/11299/638. Accessed December 2020

Ford, Alistair, Stuart L. Narr, Richard J. Dawson, and Philip James. 2015. "Transport Accessibility Analysis Using GIS: Assessing Sustainable Transport in London." ISPRS International Journal of Geo-Information 4(1):124-49. doi 10.3390/ ijgi4010124. 
Geurs, Karst T., and Bert Van Wee. "Accessibility Evaluation of Land-use and Transport Strategies: Review and Research Directions." Journal of Transport Geography 12(2):127-40.

Hansen, Walter G. 1959. "How Accessibility Shapes Land Use." Journal of the American Institute of Planners 25(2):73-76.

Kasehyani, Nur Hanis, Noorhazlinda Abd Rahman, Nur Sabahiah Abdul Sukor, Herni Halim, Herda Yati Katman, and Muhammad Salleh Abustan. 2019. "Evaluation of Pedestrian Walking Speed in Rail Transit Terminal." International Journal of Integrated Engineering Vol. 11 No. 9 (2019) 026-036.

Kraft, Stanislav. 2016. "Measuring and Modelling the Spatial Accessibility of Public Transport Stops in GIS." Hungarian Geographical Bulletin 65(1):57-69. DOI: 10.15201/hungeobull.65.1.5

Levinson, David. 2002. "Identifying Winners and Losers in Transportation." Transportation Research Record 1812(1):179-85.

Lovett, Andrew, Robin Haynes, Gisela Sünnenberg, and Susan Gale. 2002. "Car Travel Time and Accessibility by Bus to General Practitioner Services: A Study Using Patient Registers and GIS." Social Science \& Medicine 55(1):97-111.

Mavoa, Suzanne, Karen Witten, Tim McCreanor, and David O'Sullivan. 2012. "GIS Based Destination Accessibility Via Public Transit and Walking in Auckland, New Zealand." Journal of Transport Geography 20(1):15-22.
Ministry of Municipal and Rural Affairs (MoMRA). 2019. "Engineering Design Handbook." https:// www.momra.gov.sa/sites/default/files/202003/\%D8\%AF\%D9\%84\%D9\%8A\%D9\%84\%20\%D8\% A7\%D9\%84\%D8\%AA\%D8\%B5\%D9\%85\%D9\%8 A\%D9\%85\%20\%D8\%A7\%D9\%84\%D9\%87\%D9 \%86\%D8\%AF\%D8\%B3\%D9\%8A.pdf (accessed September 1, 2020).

O'Sullivan, David, Alastair Morrison, and John Shearer. 2000. "Using Desktop GIS for the Investigation of Accessibility by Public Transport: An Isochrone Approach." International Journal of Geographical Information Science 14(1):85-104.

Poelman, Hugo, and Lewis Dijkstra. 2015.

"Measuring Access to Public Transport in European Cities." Regional and Urban Policy Working Paper 01/2015. Accessed December 15, 2020. https:// ec.europa.eu/regional_policy/sources/docgener/ work/2015_01_publ_transp.pdf

Riyadh Metro. 2020a. "Bus Metro Overview." Accessed December 15, 2020. http://riyadhmetro.sa/ en/buses/

- - . 2020b. "Riyadh Metro Overview." Accessed

December 15, 2020. http://riyadhmetro.sa/en/metro/

Royal Commission for Riyadh City (RCRC). 2012. "King Abdulaziz Project for Riyadh Public Transport." Accessed December 15, 2020. https://www.rcrc.gov. sa/en/projects/riyadh-metro

TomTom Traffic Index. 2020. "Riyadh Traffic." Accessed December 2020. https://www.tomtom. com/en_gb/traffic-index/riyadh-traffic/ 
United Nations Human Settlements Programme (UN-Habitat). 2019. "Saudi Cities Report 2019." Accessed December 15, 2020. https://unhabitat.org/ sites/default/files/2020/05/saudi_city_report.english. pdf

Vision 2030. 2018. "National Transformation Program." Accessed December 15, 2020. https:// vision2030.gov.sa/sites/default/files/attachments/ NTP\%20English\%20Public\%20Document_2810.pdf
Weisbrod, Glen, and Arlee Reno. 2009. Economic Impact Of Public Transportation Investment. Washington, DC: American Public Transport Association.

Zhao, Fang, Lee-Fang Chow, Min-Tang Li, Ike Ubaka, and Albert Gan. 2003. "Forecasting Transit Walk Accessibility: Regression Model Alternative to Buffer Method." Transportation Research Record 1835(1):34-41. 


\title{
About the Authors
}

\begin{abstract}
Alma Al Hussaini
Alma is a researcher in the transport field. She holds a bachelor's degree in mechanical engineering from Boston University. Alma was on a secondment at KAPSARC for a year where she worked on the KAPSARC Spatial Urban Energy System project. Her research focuses on assessing factors that influence the modal switch to public transportation in Riyadh.
\end{abstract}

\section{Nourah Al Hosain}

Nourah is a senior research analyst in KAPSARC's Policy and Decision Science program. She is currently working with the KAPSARC Toolkit for Behavioral Analysis (KTAB) development team and is also part of KAPSARC's GIS team. Nourah holds a Bachelor of Science in computer science from Prince Sultan University.

\section{About the Project}

This study is part of the ongoing project "KAPSARC Spatial Urban Energy System." The project aims to develop a spatial urban energy system framework for Riyadh, entailing the development of two streams of statistical and spatial models. The first model assesses the change in energy consumption in the Transit-Oriented Development (TOD) area proposed by the Royal Commission for Riyadh City (RCRC). The second model frames the interaction between economic activities, land-use, transportation and energy efficiency. 
INAPSARC

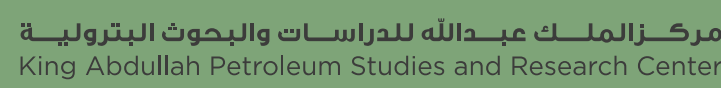

www.kapsarc.org 